\title{
POSSIBILITIES OF USING BY-PRODUCTS IN THE CIRCULAR PRODUCTION PROCESS IN BIOGAS POWER PLANTS
}

\section{Nikola Dražić*, Gordana Dražić \\ Nikola Rakašćan}

Singidunum University, Belgrade, Serbia

\begin{abstract}
:
A biogas power plant uses biomass (manure, silage) to produce biogas for energy conversion to electricity and heat and digestate as byproduct of the anaerobic digestion process. The production of first generation agro-energy crops, as basic raw materials for silage, should be organized on marginal land. The application of solid digestate on such land should enable an increase in yield of agro-energy crops, avoiding the use of mineral fertilizers. By applying this concept, advantages are achieved for the management of the biogas power plant through the reduction of operating costs (economic advantages): mineral fertilizer is substituted by a by-product from own production, a production chain is established on the nearest land; environmental significance (environmental benefits): reduced greenhouse gas emissions into the atmosphere; improving the production capacity of degraded land; and general social (social advantages): mitigation of climate change using renewable energy sources - biomass and improvement of production capacities (valorization) of degraded lands.
\end{abstract}

Keywords:

anaerobic digestion, bioeconomy, biomass, sustainability.

\section{INTRODUCTION}

Biogas power plant works on a base principle of using organic material as an entry substance to make energy in the form of biogas while co-products of the system are extracted and reused. This type of powerplant usually uses the process of Anaerobic digestion (AD). This process is based on a biochemical reaction that uses organic matter and with the help of microorganisms, in the absence of oxygen, produces a gas that is made of methane and carbon dioxide. The byproduct of this process is called digestate or sludge and it can contain certain chemical characteristics that can make it suitable for reuse in the fields of agriculture and farm industry (Maurer 2019; Li et al. 2017).

Feedstock for the biogas production is made from organic materials that are usually leftovers and are usually considered a waste. The main sources of feedstock materials are waste from industry, manure, leftover foods, wastewater plants sludge, energy crops, source-separated organics (SSO), municipal solid waste (MSW), and organic matter from landfills. Some feedstock needs to be treated before entering biogas plant production (De Meesteret al. 2012). The environmental sustainability of anaerobic digestion as a biomass valorization technology. Production of biogas is done in the digestion tank by the process of anaerobic digestion. The biogas is created in one stream and it can be used for electrical energy production or as a renewable fuel for vehicles. Second product from the plant is extracted in the second stream and it's called digestate and usually, it can be used as a fertilizer or in the making of compost, if it is in solid form, or as reusable water for plants if it is a liquid form (Kirubakarana et al 2009). 
The market for biogas is constantly growing. The social demand for cleaner energy with less impact on the environment is making initiatives across Europe for more projects that reinforce renewable energy sources among which is a biogas production. According to Global Market Insights (gminsights.com), the market value for 2019 was more than $\$ 45$ billion and it is expected that this market value will grow and the prognosis for it is to reach more than $\$ 75$ billion by the year 2026. Those predictions are supported by the growth of circular economy projects in European Union countries and they as well have grown in the last decade.

Biogas production by the system of anaerobic digestion is a perfect example of a circular economy. In this sense the first generation of agro energy crops is used for a feedstock. This type of crops can be combined with agricultural waste or other organic matter forms agriculture to enhance the production of biogas. The digestate from the plant can be used as a fertilizer for other crops or it can be reintroduced in the process as a feedstock depending on the quality of digestate and mineral and organic composition of it. If agro energy crops are grown on marginal or degraded land, it is multi-beneficial for the farmer; firstly the process of reclamation of the land, lowering the waste of the crops that are usually not used, production of biogas that can be used for electricity production or as a fuel in farm machinery, and having fertilizer or compost from digestate (Amen et al. 2017). This system looks similar to natural processes that happen in ecosystem and it is a good example of that what the circular economy has as a goal, to recycle and reuse in order to lower waste and lower ecosystem footprint.

When the biogas power plant transforms biogas into electrical energy, and by the process of cogeneration, the result is 70\% electrical and 30\% of thermal energy that is re-used in the process of creating electrical energy in the plant (Bogdanov et al 2016).

Biogas production gives a sustainable way to produce clean energy by recycling input materials and producing minimal waste and by-products. Countries that use this type of energy production are in appliance with United Nations Sustainable Development Goals (SDG's) and as well, if in Europe, with European growth and development strategies (Scarlat et al 2018).

\section{SOCIO-ECONOMIC ASPECTS}

Since the beginning of the $21^{\text {st }}$ century, the global awareness of fossil fuel usage and environmental impacts of it started to make changes in the way developed countries approach energy production. Social pressures started to point out the advantages of using renewable energy sources as well as the usage of green energy. Advocates for this approach pointed out not only the environmental impacts of cleaner energy production but the economic impacts as well (Prask et al 2018).
The circular economy is one way that is shown that can have a positive impact on the environment and empower workers in the industry in the sense that this type of economy connects different branches of industry and provides steady job opportunities. In this manner, yesterday's waste is today's input to the production process. Like in nature, the circular economy advocates the usage and re-usage of matter that was previously considered not to be usable anymore and aims to make a circular production cycle without waste, or at least, with less waste as it is possible (Cucchiella et al 2016).

If we look at the biogas production process only as making biogas in the biogas plant and take into consideration only the personnel that works at the plant, we would leave out the big part of the biogas production process. The correct way to look on the biogas production is to take into consideration all different sources that are included in the input of the plant. The agricultural industry takes a big part in feedstock production, mainly as a provider of agro energy crops of first-generation. If we utilize the production of agro energy crops on marginal lands, the valuable space for producing food is saved and there are possibilities for phytoremediation if correct crops are used (Scarlat et al 2019)

\section{BIOGAS PLANT IN SERBIA}

The Republic of Serbia started to incurring the production of green energy in the last decade with the program of state-initiated feeding tariffs. This trend was in accordance with the government's path to become a member of the European Union. This change in politics regarding energy production opened the way for new technologies and new jobs in the industry. The effort of creating more biogas plants was supported by the EU member states from which, Germany took the main initiative. According to Bioenergy Serbia (bioenergy-serbia.rs), there are 22 biogas plants currently operating in the Republic of Serbia with a total production of $21 \mathrm{MW}$. The production of energy from biogas is done in 59 biogas power plants that have been established since 2011 according to the registry of privileged energy producers in Serbia (mre.gov.rs/doc/registar-271219). As the establishment of biogas production plants and powerplants that use biogas have a rising trend and it is supported by the government, we can expect more energy production from this type of source and more job opportunities in this sector with the usage of new technologies.

As we mentioned previously, incorrect assumption would be to say that nowadays biogas plants are mostly automated and don't require skilled workers.

As the good practices and experience from EU countries like Germany, Czech Republic, Austria, Hungary and others, in production of biogas were taken, biogas plants in Serbia also transformed to better utilize technology and manpower. 
Also, we need to understand that biogas production isn't only focused on personnel in the plant, it is focused, as well, on all workers that provide feedstock (from agriculture or other industries).

Feedstocks in biogas plants in Serbia are mainly from agro energy crops and agricultural waste. To have required biomass for the plant usage, it is needed to have developed agricultural industry regarding agro energy crops production and needed logistics for transportation and treatment of agricultural waste. Entry operations like growing agro energy crops, gathering agricultural waste, and treatment of it require mostly low-skill workforce. Those operations are considered to be a part of the agriculture industry and are the most important for the production of biogas. When desired feedstock is gathered, it is sorted out on the factory grounds and prepared for the process of anaerobic digestion.

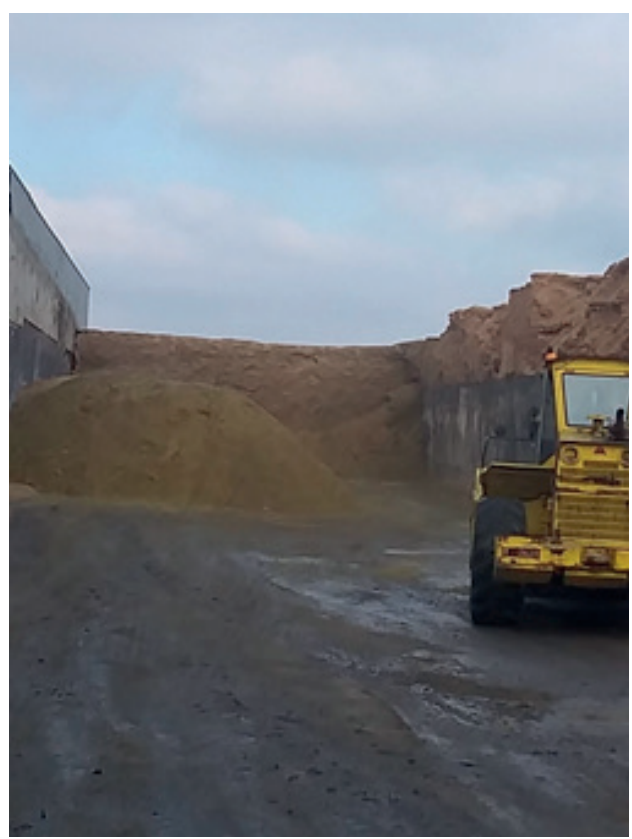

Picture 1. Biogas plant feedstock area, original source N.R. 2019.

The preparation stage requires low and medium-skill workers and the usage of heavy machinery. If the treatment of feedstock is needed, like in the case of manure or other types of agricultural waste, medium skill workers are needed along with the usage of chemical agents. By reusing leftovers, waste, or by-products of another industry, there are no expenses on storage, disposition, or destruction of those materials. The structure has been changed in a way that those materials become the biogas production lifeline, and the stance of losing money has changed for other industries since now they have a resource which empowers that industry and allows it to hire and maintain more workers.
The next stage in the biogas plant is the production of biogas. Inside the plant, all processes are highly mechanized and require high-skill workers to operate them. Anaerobic digestion is done in the digestion tank. Almost all processes from the input area are automatized until the end of the production. In those areas highly trained personnel watches over the process of the production. The biogas plant requires highly skilled technicians as well, in the case of malfunctions, or errors. Employees in this area need to be up to date with all safety standards and to have knowledge of the new components in the plants. Good practices and experiences from countries and companies that are leaders in this industry are constantly shared. 

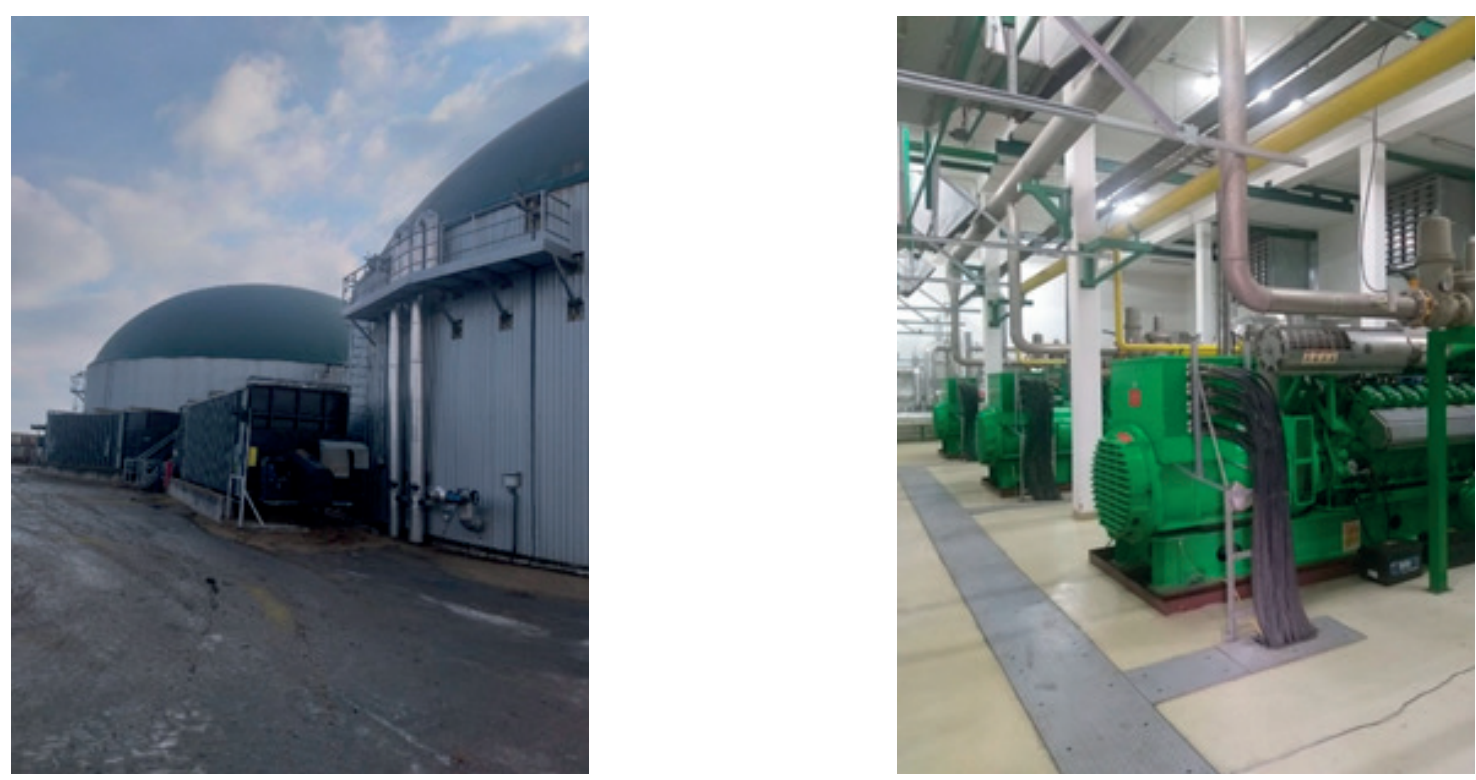

Picture 2. and 3. Biogas digestion tank (left) and electric generator (right), original source N.R. 2019

The final product is biogas that is mostly used for the production of electrical energy in Serbia. Biogas can also find usage in the production of thermal energy or as fuel. When using biogas to produce electrical energy, the production is based on cogeneration process with $70 \%$ of electrical energy made and $30 \%$ of heat. Cogeneration is needed to ensure profitability of producing electrical energy from biogas since without it, entire process would have financial losses. The by-product of producing biogas is called digestate. This substance can be used for multiple things depending on its quality; chemical and mineral characteristics. In Serbia, digestate is mainly used as a fertilizer. The biogas plant can sell its by-product to a third party, it can reuse it on its own agricultural land or sell it back to the providers of feedstocks. Previously, digestate was considered a waste and was deposited, and with the growth of the circular economy, the processes are continuously growing and expanding in a way to make a close-ended loop.

\section{CONCLUSION}

The circular economy is based on the natural cycle that is found in every ecosystem. The main idea is the implementation of the no-waste policy in human society. By transforming the waste into the resource, we are simultaneously encouraging growth in multiple industries while reinforcing the main industry. With the approach of the circular economy and new ways of thinking, there is an opportunity to create new industry branches while securing more jobs and promoting educational and professional growth.

Biogas plants are one of good example of producing green energy by the principles of the circular economy. Biogas plants can't stand without other industry inputs, the feedstock is needed for the production and they have a valuable output that can be reused. Connectivity with other industries promotes new hiring as well as education in all branches. This results in bridging gaps among different types of industries and promotes new skills needed for making this complex system work. Taking into consideration all previously mentioned, production of biogas cannot be a standalone process, it combines the agricultural and energy industry with environment protection in circular economy.

\section{LITERATURE}

Li M., Luo N., Lu Y, (2017): Biomass Energy Technological Paradigm (BETP): Trends in This Sector. Sustainability, 9, 567.

Ameen A., Yang X., Chen F., Tang C., Du F., Fahad S., Hui Xie G. (2017): Biomass Yield and Nutrient Uptake of Energy Sorghum in Response to Nitrogen Fertilizer Rate on Marginal Land in a Semi-Arid Region. Bioenerg. Res., 10, 363.

Maurer C., Seiler-Petzold J., Schulz R., Müller J. (2019): ShortTerm Nitrogen Uptake of Barley from Differently Processed Biogas Digestate in Pot Experiments, Energies, 12, 696; doi:10.3390/en12040696

De Meester S.,Demeyer J., Velghe F., Peene A., Van Langenhove H., Dewulf J. (2012): The environmental sustainability of anaerobic digestion as a biomass valorization technology. Bioresource Technology, 121, 396-403

Kirubakarana V., Sivaramakrishnanb V., Nalinic R., Sekard T., Premalathae M., Subramaniane, P. (2009): A review on gasification of biomass. Renewable and Sustainable Energy Reviews, 13, 179,

Prask H., Szlachta J., Fugol M., Kordas L., Lejman A., Tuznik F., Tuznik F. (2018): Sustainability Biogas Production from Ensiled Plants Consisting of the Transformation of the Digestate into a Valuable Organic-Mineral Granular Fertilizer. Sustainability, 10, 585, 
Scarlat N., Fahl F.,Dallemand J-F., Monforti F., Motola V. (2018): A spatial analysis of biogas potential from manure in Europe. Renewable and Sustainable Energy Reviews, 94, 915.

F. Cucchiella, I. D’Adamo, M. Gastaldi. (2016) Optimizing plant size in the planning of renewable energy portfolios. Letters in Spatial and Resource Sciences. 9 169-87

D. Bogdanov, C. Breyer. (2016) North-East Asian Super Grid for $100 \%$ renewable energy supply: Optimal mix of energy technologies for electricity, gas and heat supply options. Energy Conversion and Management. 112 176-90.
Scarlat, N. Highlights of the Conference. In Proceedings of the $27^{\text {th }}$ European Biomass Conference \& Exhibition, 2019, Lisbon, Portugal, http://programme.eubce.com/search. php? close $=$ all

www.bioenergy-serbia.rs accessed september 2020

www.gminsights.com accessed september 2020

www.mre.gov.rs/doc/registar-271219 accessed september 2020 